\title{
The effects of synbiotic supplementation on hormonal status, biomarkers of inflammation and oxidative stress in subjects with polycystic ovary syndrome: a randomized, double-blind, placebo- controlled trial
}

Khadijeh Nasri ${ }^{1}$, Mehri Jamilian ${ }^{1}$, Elham Rahmani ${ }^{1}$, Fereshteh Bahmani ${ }^{2}$, Maryam Tajabadi-Ebrahimi ${ }^{3}$ and Zatollah Asemi ${ }^{2 *}$

\begin{abstract}
Background: To our knowledge, no reports are available indicating the effects of synbiotic supplementation on hormonal status, biomarkers of inflammation and oxidative stress in subjects with polycystic ovary syndrome (PCOS). This research was done to assess the effects of synbiotic supplementation on hormonal status, biomarkers of inflammation and oxidative stress in subjects with PCOS.
\end{abstract}

Methods: This randomized double-blind, placebo-controlled trial was conducted on 60 subjects diagnosed with PCOS according to the Rotterdam criteria. Subjects were randomly assigned into two groups to take either synbiotic $(n=30)$ or placebo $(n=30)$ for 12 weeks. Endocrine, inflammation and oxidative stress biomarkers were quantified at baseline and after the 12-week intervention.

Results: After the 12-week intervention, compared with the placebo, synbiotic supplementation significantly increased serum sex hormone-binding globulin (SHBG) (changes from baseline in synbiotic group: $+19.8 \pm 47.3$ vs. in placebo group: $+0.5 \pm 5.4 \mathrm{nmol} / \mathrm{L}, p=0.01$ ), plasma nitric oxide $(\mathrm{NO})$ (changes from baseline in synbiotic group: $+5.5 \pm 4.8$ vs. in placebo group: $+0.3 \pm 9.1 \mu \mathrm{mol} / \mathrm{L}, p=0.006)$, and decreased modified Ferriman Gallwey (mF-G) scores (changes from baseline in synbiotic group: $-1.3 \pm 2.5$ vs. in placebo group: $-0.1 \pm 0.5, p=0.01$ ) and serum high-sensitivity C-reactive protein (hs-CRP) (changes from baseline in synbiotic group: $-950.0 \pm 2246.6$ vs. in placebo group: $+335.3 \pm 2466.9 \mathrm{ng} / \mathrm{mL}, p=0.02$ ). We did not observe any significant effect of synbiotic supplementation on other hormonal status and biomarkers of oxidative stress.

Conclusions: Overall, synbiotic supplementation for 12 weeks in PCOS women had beneficial effects on SHBG, mFG scores, hs-CRP and NO levels, but did not affect other hormonal status and biomarkers of oxidative stress.

Trial registration: This study was retrospectively registered in the Iranian website (www.irct.ir) for registration of clinical trials (IRCT201509115623N53), on 2015-09-27.

Keywords: Synbiotic, Hormonal status, Inflammation, Oxidative stress, Polycystic ovary syndrome

\footnotetext{
*Correspondence: asemi_r@yahoo.com

${ }^{2}$ Research Center for Biochemistry and Nutrition in Metabolic Diseases,

Kashan University of Medical Sciences, Kashan, IR, Iran

Full list of author information is available at the end of the article
}

(c) The Author(s). 2018 Open Access This article is distributed under the terms of the Creative Commons Attribution 4.0 International License (http://creativecommons.org/licenses/by/4.0/), which permits unrestricted use, distribution, and reproduction in any medium, provided you give appropriate credit to the original author(s) and the source, provide a link to the Creative Commons license, and indicate if changes were made. The Creative Commons Public Domain Dedication waiver (http://creativecommons.org/publicdomain/zero/1.0/) applies to the data made available in this article, unless otherwise stated. 


\section{Background}

Polycystic ovary syndrome (PCOS) is a common gynecological endocrine disorder related to irregular menstrual cycles and androgen excess affecting 6-12\% of premenopausal women [1]. It was reported that several pro-inflammatory factors and mediators increase in subjects with PCOS, including C-reactive protein (CRP), leukocytes, cytokines, and reactive oxygen species [2]. Inflammation and oxidative stress are associated with obesity, type 2 diabetes mellitus (T2DM), hyperandrogenemia, insulin resistance as well as an increased risk of cardiovascular disease (CVD) [3].

Nowadays, there is a growing interest to use synbiotics and probiotics in diseases related to metabolic syndrome [4]. The basis of this interest derives mostly from the results of nutritional intervention studies suggest that synbiotics intake have beneficial effects on metabolic profiles, biomarkers of inflammation and oxidative stress among patients with gestational diabetes (GDM) [5], T2DM [6] and cancer [7]. In addition, gut microbiota may participate in the whole-body metabolism by affecting energy balance, insulin metabolism and inflammation related to metabolic disorders [8]. We have previously shown that consumption of the synbiotic bread for 8 weeks among participants with T2DM had beneficial effects on plasma nitric oxide (NO) and malondialdehyde (MDA) concentrations, but did not influence plasma total antioxidant capacity (TAC) and glutathione (GSH) values [9]. In another study by Ipar et al. [10], it was seen that synbiotic supplementation for 30 days in obese children had beneficial effects on lipid fractions and total oxidative stress. However, multispecies probiotics supplementation $\left(10^{10} \mathrm{CFU} /\right.$ day $)$ for 14 weeks did not affect biomarkers of inflammation and oxidative stress among trained men [11].

Synbiotics and probiotics may affect metabolic parameters through the effect on the production of short chain fatty acid (SCFA), decreased gene expression of inflammatory factors [12], and increased synthesis of GSH, apoptosis induction and up-regulation of oxidative pentose pathway activity [13]. To our knowledge, no reports are available indicating the effects of synbiotic supplementation on hormonal, inflammatory and oxidative parameters in subjects with PCOS. The objective of this study was to evaluate the effects of synbiotic supplementation on hormonal, inflammatory and oxidative parameters in these patients.

\section{Methods}

\section{Trial design and participants}

This randomized, double-blinded, placebo-controlled clinical trial, registered in the Iranian clinical trials website at: (http://www.irct.ir: IRCT201509115623N53). This study was conducted among 60 women with PCOS diagnosed according to the Rotterdam criteria [14, 15], aged 18-40 years who referred to the Kossar Clinic in Arak, Iran, from April to June 2016. Main exclusion criteria were: smokers, taking probiotic and/or synbiotic supplements, pregnant women, endocrine diseases including thyroid, diabetes and/or impaired glucose tolerance as well as gastrointestinal problems in the study.

\section{Ethics approval and consent to participate}

The study was followed the Declaration of Helsinki guideline and was approved by the ethics committee of the Arak University of Medical Sciences (AUMS), Arak, Iran. Informed consent was taken from all subjects.

\section{Study protocol}

At first, women were randomly allocated to receive either synbiotic supplements or placebo $(n=30$ each group) for 12 weeks. Duration of the treatment was selected based on observed beneficial effects of probiotic supplementation on metabolic profiles in women with PCOS [16]. Randomization was done using computergenerated random numbers by a trained staff at the gynecology clinic. Randomization and allocation were concealed to the researchers and participants until the final analyses were completed. Synbiotic supplements were containing Lactobacillus acidophilus, Lactobacillus casei and Bifidobacterium bifidum $\left(2 \times 10^{9} \mathrm{CFU} / \mathrm{g}\right.$ each $)$ plus $0.8 \mathrm{~g}$ inulin. Synbiotic supplements and the placebo were manufactured by Tak Gen Zist Pharmaceutical Company (Tehran, Iran) and Barij Essence Pharmaceutical Company (Kashan, Iran), respectively. The compliance rate during the intervention was monitored by a brief daily cell phone reminder to take the supplement and asking the subjects to return the supplement containers. All participants completed a 3days food record and physical activity records as metabolic equivalents (METs) prior to intervention, at weeks 3, 6, 9 and 12 of the treatment. Daily macro- and micro-nutrient intakes were calculated by analyzing food data using nutritionist IV software (First Databank, San Bruno, CA) [17].

\section{Anthropometric parameters}

Anthropometric measurements were determined in a fasting status using a standard scale (Seca, Hamburg, Germany) at baseline and after the 12-week treatment. Body mass index (BMI) was calculated as weight in $\mathrm{kg}$ divided by height in meters squared.

\section{Clinical assessments}

Clinical parameters included determinations of hirsutism using a mFG scoring system [18]. 


\section{Biochemical evaluation}

At pre- and post-treatment, $10 \mathrm{~mL}$ blood were collected from each subject at Arak reference laboratory. Hormonal profiles were determined using an Elisa kits (DiaMetra, Milano, Italy) with inter- and intra-assay coefficient variances $(\mathrm{CVs})$ lower than $7 \%$. Free androgen index (FAI) was calculated based on suggested formulas. High sensitivity C-reactive protein (hs-CRP) and insulin values were assessed by ELISA kits (LDN, Nordhorn, Germany) and (Monobind, California, USA), respectively. The plasma NO [19], TAC [20], GSH [21] and MDA levels [22] were determined by the spectrophotometric method with inter- and intra-assay CVs less than $5 \%$. To determine fasting plasma glucose, we used Pars Azmun kit, Tehran, Iran. The homeostatic model of assessment for insulin resistance (HOMA-IR) was determined according to suggested formulas [23].

\section{Sample size}

We used a randomized clinical trial sample size formula with type one $(\alpha)$ and type two errors $(\beta)$ to be 0.05 and the power of $80 \%$ to calculate sample size. Based on a previous study [24], we used a standard deviation (SD) of $283.7 \mathrm{ng} / \mathrm{mL}$ and a difference in mean (d) of 230 . $0 \mathrm{ng} / \mathrm{mL}$, considering hs-CRP levels as the key variable. According to the calculation 25 women should be enrolled in each group. Assuming a dropout of 5 subjects per group, the final sample size was considered to be 30 per treatment group.

\section{Statistical methods}

The Kolmogorov-Smirnov test was performed to determine the normality of data. Outcome log-transformation was used if model residual has non-normal distribution (hs-CRP, MDA, SHBG and FAI). To detect differences in anthropometric parameters as well as in macro- and micro-nutrient intakes between the two groups, we applied independent $t$-test. To assess the effects of synbiotic supplementation on metabolic parameters, we used one-way repeated measures analysis of variance. Adjustment for changes in baseline values of biochemical parameters, age and baseline BMI was performed by analysis of covariance (ANCOVA). P-values $<0.05$ were considered statistically significant. All statistical analyses were done using the Statistical Package for Social Science version 18 (SPSS Inc., Chicago, Illinois, USA).

\section{Results}

In this study, all 60 subjects [synbiotic and placebo $(n=$ 30 each group)] completed the trial (Fig. 1). The compliance rate in this study was high; more than $90 \%$ of capsules were taken during the course of the trial in both groups. No side effects were reported following the intake of synbiotic supplements in patients with PCOS.

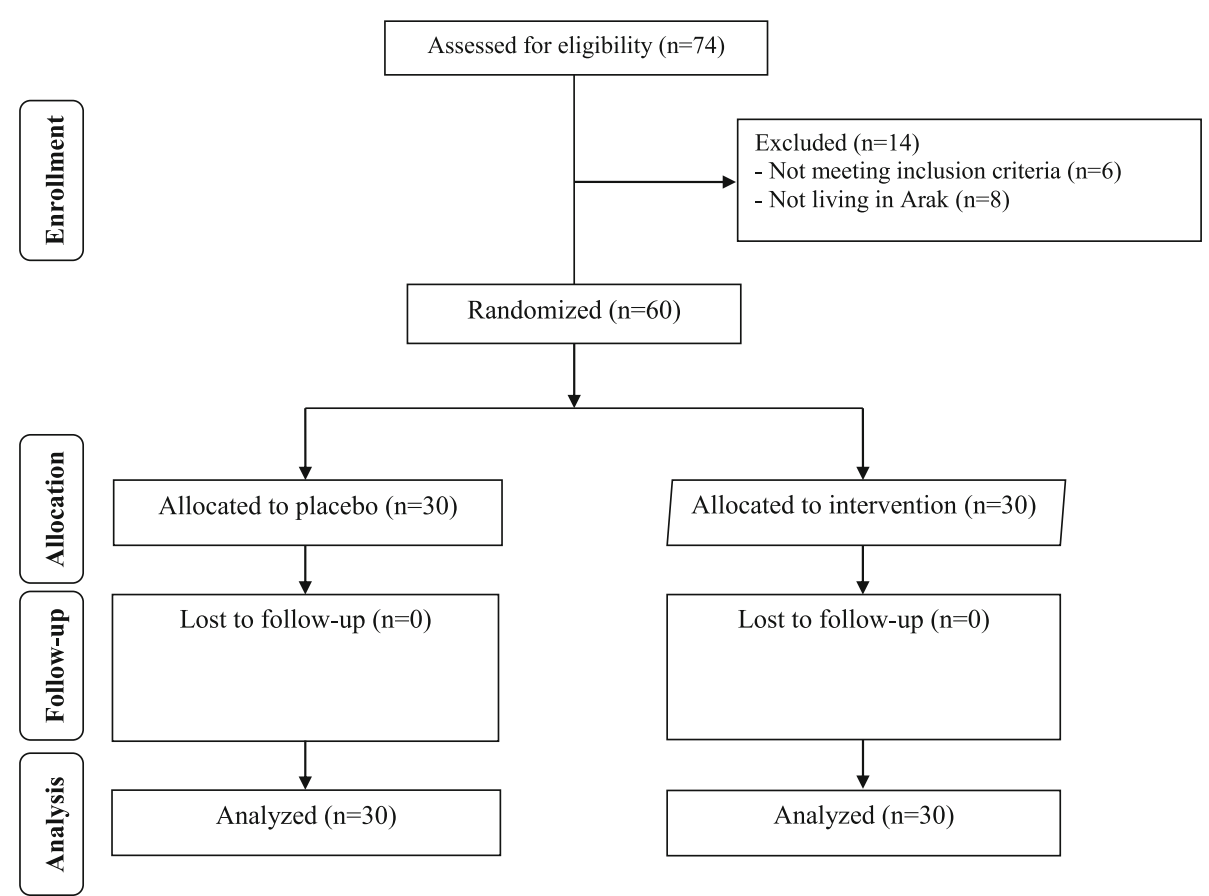

Fig. 1 Summary of patient flow diagram 
Table 1 General characteristics of study participants

\begin{tabular}{llll}
\hline & Placebo group $(n=30)$ & Synbiotic group $(n=30)$ & $p^{\text {a }}$ \\
\hline Age $(\mathrm{y})$ & $25.9 \pm 5.2$ & $25.7 \pm 5.5$ & 0.90 \\
Height $(\mathrm{cm})$ & $163.3 \pm 6.6$ & $161.4 \pm 5.8$ & 0.25 \\
Weight at study baseline $(\mathrm{kg})$ & $72.4 \pm 14.1$ & $71.4 \pm 11.6$ & 0.79 \\
Weight at end-of-trial $(\mathrm{kg})$ & $71.9 \pm 14.4$ & $-0.3 \pm 11.4$ & 0.83 \\
Weight change $(\mathrm{kg})$ & $-0.4 \pm 1.0$ & $27.4 \pm 4.0$ & 0.53 \\
BMl at study baseline $\left(\mathrm{kg} / \mathrm{m}^{2}\right)$ & $27.2 \pm 5.3$ & $27.3 \pm 3.9$ & 0.84 \\
BMl at end-of-trial $\left(\mathrm{kg} / \mathrm{m}^{2}\right)$ & $27.0 \pm 5.4$ & $-0.1 \pm 0.4$ & 0.80 \\
BMl change $\left(\mathrm{kg} / \mathrm{m}^{2}\right)$ & $-0.2 \pm 0.3$ & $27.7 \pm 2.1$ & 0.49 \\
MET-h/day at study baseline & $27.5 \pm 2.0$ & $27.8 \pm 2.3$ & 0.60 \\
MET-h/day at end-of-trial & $27.6 \pm 2.2$ & $0.04 \pm 1.0$ & 0.69 \\
MET-h/day change & $0.1 \pm 0.6$ & & 0.83 \\
\hline
\end{tabular}

Data are means \pm SDs

${ }^{\text {a } O b t a i n e d ~ f r o m ~ i n d e p e n d e n t ~} t$ test. METs, metabolic equivalents

Mean age, height, and weight, BMI and METs at baseline and end-of-trial were not statistically different between the two groups (Table 1).

No significant difference in mean dietary macro- and micro-nutrient intakes between the two groups was seen (Data not shown).

Compared with the placebo, synbiotic supplementation significantly increased serum sex hormone-binding globulin (SHBG) (changes from baseline in synbiotic group: + $19.8 \pm 47.3$ vs. in placebo group: $+0.5 \pm 5.4 \mathrm{nmol} / \mathrm{L}, p=0$. 01 ), plasma $\mathrm{NO}$ (changes from baseline in synbiotic group: $+5.5 \pm 4.8$ vs. in placebo group: $+0.3 \pm 9.1 \mu \mathrm{mol} / \mathrm{L}, p=0$. 006), and decreased $\mathrm{mF}-\mathrm{G}$ scores (changes from baseline in synbiotic group: $-1.3 \pm 2.5$ vs. in placebo group: $-0.1 \pm$ $0.5, p=0.01$ ), FAI (changes from baseline in synbiotic group: $-0.12 \pm 0.29$ vs. in placebo group: $-0.01 \pm 0.08, p$
$=0.01$ ) and serum hs-CRP (changes from baseline in synbiotic group: $-950.0 \pm 2246.6$ vs. in placebo group: +335 . $3 \pm 2466.9 \mathrm{ng} / \mathrm{mL}, p=0.02$ ) (Table 2). In addition, compared with the placebo, synbiotic supplementation resulted in a significant reduction in serum insulin levels (changes from baseline in synbiotic group: $-1.6 \pm 2.9$ vs. in placebo group: $+0.4 \pm 2.3 \mu \mathrm{IU} / \mathrm{mL}, p=0.003$ ), HOMAIR (changes from baseline in synbiotic group: $-0.4 \pm 0.7$ vs. in placebo group: $+0.1 \pm 0.5, p=0.003$ ). A trend toward a greater decrease in total testosterone (changes from baseline in synbiotic group: -0.4 vs. in placebo group: $-0.1 \mathrm{ng} / \mathrm{mL}, p=0.09)$ and plasma MDA concentrations (changes from baseline in synbiotic group: $-0.2 \pm$ 0.1 vs. in placebo group: $+0.5 \pm 1.4 \mu \mathrm{mol} / \mathrm{L}, p=0.05$ ) was observed in synbiotic group compared with placebo group. We did not observe any significant effect of

Table 2 Hormonal status, biomarkers of inflammation and oxidative stress at baseline and after the 12-week intervention in subjects with polycystic ovary syndrome

\begin{tabular}{|c|c|c|c|c|c|c|c|}
\hline & \multicolumn{3}{|c|}{ Placebo group $(n=30)$} & \multicolumn{3}{|c|}{ Synbiotic group $(n=30)$} & \multirow[t]{2}{*}{$p^{a}$} \\
\hline & Baseline & End-of-trial & Change & Baseline & End-of-trial & Change & \\
\hline Total testosterone $(\mathrm{ng} / \mathrm{mL})$ & $2.4 \pm 1.2$ & $2.3 \pm 1.0$ & $-0.1 \pm 0.5$ & $2.8 \pm 1.3$ & $2.4 \pm 0.9$ & $-0.4 \pm 0.9$ & 0.09 \\
\hline SHBG (nmol/L) & $38.3 \pm 17.3$ & $38.8 \pm 17.6$ & $0.5 \pm 5.4$ & $37.3 \pm 13.1$ & $57.1 \pm 48.6$ & $19.8 \pm 47.3$ & 0.01 \\
\hline FAl & $0.27 \pm 0.21$ & $0.25 \pm 0.16$ & $-0.01 \pm 0.08$ & $0.33 \pm 0.36$ & $0.21 \pm 0.14$ & $-0.12 \pm 0.29$ & 0.01 \\
\hline mF-G scores & $15.1 \pm 3.8$ & $15.0 \pm 3.7$ & $-0.1 \pm 0.5$ & $15.3 \pm 5.6$ & $14.0 \pm 4.9$ & $-1.3 \pm 2.5$ & 0.01 \\
\hline DHEAS $(\mu \mathrm{g} / \mathrm{mL})$ & $2.6 \pm 1.3$ & $2.5 \pm 1.1$ & $-0.1 \pm 0.4$ & $2.6 \pm 1.5$ & $2.2 \pm 0.8$ & $-0.4 \pm 1.1$ & 0.40 \\
\hline hs-CRP (ng/mL) & $2990.7 \pm 2510.7$ & $3326.0 \pm 2791.1$ & $335.3 \pm 2466.9$ & $2920.0 \pm 2251.2$ & $1970.0 \pm 1442.0$ & $-950.0 \pm 2246.6$ & 0.02 \\
\hline $\mathrm{NO}(\mu \mathrm{mol} / \mathrm{L})$ & $40.5 \pm 8.7$ & $40.8 \pm 9.3$ & $0.3 \pm 9.1$ & $39.0 \pm 3.1$ & $44.5 \pm 5.0$ & $5.5 \pm 4.8$ & 0.006 \\
\hline TAC (mmol/L) & $868.7 \pm 158.4$ & $877.9 \pm 149.9$ & $9.2 \pm 119.3$ & $773.1 \pm 38.7$ & $818.2 \pm 57.5$ & $45.1 \pm 51.8$ & 0.13 \\
\hline $\mathrm{GSH}(\mu \mathrm{mol} / \mathrm{L})$ & $494.2 \pm 85.5$ & $521.5 \pm 117.2$ & $27.3 \pm 117.8$ & $498.9 \pm 56.8$ & $523.5 \pm 53.4$ & $24.7 \pm 58.7$ & 0.91 \\
\hline MDA $(\mu \mathrm{mol} / \mathrm{L})$ & $2.2 \pm 0.7$ & $2.7 \pm 1.2$ & $0.5 \pm 1.4$ & $2.3 \pm 0.4$ & $2.1 \pm 0.4$ & $-0.2 \pm 0.1$ & 0.05 \\
\hline
\end{tabular}

All values are means \pm SDs

${ }^{a} P$ values represent the time $\times$ group interaction (computed by analysis of the one-way repeated measures ANOVA)

$D H E A S$ dehydroepiandrosterone sulfate, $F A$ l free androgen index, GSH total glutathione, $h s$ - $C R P$ high-sensitivity C-reactive protein, $m F$ - $G$ modified Ferriman Gallwey, MDA malondialdehyde, NO nitric oxide, SHBG sex hormone-binding globulin, TAC total antioxidant capacity 
synbiotic supplementation on other hormonal status and biomarkers of oxidative stress.

Baseline levels of plasma TAC $(p=0.002)$ were significantly different between the two groups. Therefore, we controlled the analyses for the baseline levels, age and baseline BMI. When we adjusted the analyses for baseline values of biochemical variables, age and baseline BMI, significant changes in FAI $(p=0.04)$ were observed, but other findings did not alter (Table 3 ).

\section{Discussion}

In this research, which to our knowledge is the first of its kind, we assessed the effects of synbiotic supplementation on hormonal, inflammatory and oxidative parameters among subjects with PCOS. We shown that taking synbiotic supplements for 12 weeks among PCOS subjects had beneficial effects on SHBG, mFG scores, FAI, serum insulin, HOMA-IR, serum hs-CRP and plasma NO levels, but did not affect other hormonal, inflammatory and oxidative parameters. However, observed reduction at mFG scores after 12 weeks was statistically significant, it was clinically low. Long-term interventions and higher dosage of probiotic and inulin might result in greater changes in $\mathrm{mFG}$ scores.

Subjects with PCOS are susceptible to several metabolic complications including insulin resistance and inflammation $[25,26]$. We found that synbiotic administration for 12 weeks among PCOS subjects led to a significant increase in serum SHBG values and FAI and a significant decrease in mFG scores, serum insulin levels and HOMAIR, but did not affect hormonal profiles compared with the placebo. However, to our knowledge, no reports are available indicating the effects of synbiotic supplementation on hormonal status, biomarkers of inflammation and oxidative stress in subjects with PCOS; some studies have evaluated the effects of synbiotic supplementation on markers of insulin metabolism among subjects without PCOS. We have previously shown that taking synbiotic supplements for 6 weeks among subjects with GDM had beneficial effects on markers of insulin metabolism [5]. Shoaei et al. [27] also indicated that probiotic supplementation for 12 weeks to women with PCOS significantly decreased fasting glucose and insulin concentrations. In another study conducted by Eslamparast et al. [28], it was seen that levels of fasting glucose and insulin resistance were improved significantly in the synbiotic group among subjects with metabolic syndrome after 28 weeks. In addition, the intake of synbiotic containing Lactobacillus acidophilus, Bifidobacterium bifidum and fructooligosaccharides in elderly people with T2DM resulted in a significant reduction in fasting glycemia [29]. Hyperinsulinemia and insulin resistance in women with PCOS directly stimulate ovarian steroidogenesis by acting on thecal cell proliferation and increasing secretion of androgens mediated by luteinizing hormone (LH), increased gene expression of cytochrome P450 and insulin-like growth factor 1 receptor [30]. In addition, androgens may regulate follicular atresia [31]. It was also reported that increased testosterone levels increase somatic cell atresia in rat ovaries [32]. Furthermore, hyperandrogenemia can induce inflammation in women with PCOS [33]. Therefore, synbiotic intake due to its useful effects on insulin resistance may be useful to control clinical and metabolic symptoms. Synbiotic intake might improve SHBG and mFG scores through improved insulin sensitivity, the modification of gut flora, the elevation of faecal $\mathrm{pH}$ [34] and the reduction of pro-inflammatory cytokine production [35].

Our previous study among subjects with T2DM has demonstrated that consumption of a synbiotic food for 6 weeks had significant effects on serum hs-CRP concentrations [24]. In addition, supplementation with a

Table 3 Adjusted changes in metabolic profile of the patients with polycystic ovary syndrome

\begin{tabular}{llll}
\hline & Placebo group $(n=30)$ & Synbiotic group $(n=30)$ & $p^{\text {a }}$ \\
\hline Total testosterone $(\mathrm{ng} / \mathrm{mL})$ & $-0.2 \pm 0.1$ & $-0.3 \pm 0.1$ & 0.26 \\
SHBG $(\mathrm{nmol} / \mathrm{L})$ & $0.7 \pm 6.1$ & $19.5 \pm 6.1$ & 0.03 \\
FAl & $-0.04 \pm 0.02$ & $-0.10 \pm 0.02$ & 0.04 \\
$\mathrm{mF}-\mathrm{G}$ scores & $-0.1 \pm 0.3$ & $-1.3 \pm 0.3$ & 0.007 \\
DHEAS $(\mu \mathrm{g} / \mathrm{mL})$ & $-0.1 \pm 0.1$ & $-0.3 \pm 0.1$ & 0.18 \\
$\mathrm{hs}-\mathrm{CRP}(\mathrm{ng} / \mathrm{mL})$ & $375.6 \pm 339.8$ & $-990.2 \pm 339.8$ & 0.006 \\
NO $(\mu \mathrm{mol} / \mathrm{L})$ & $0.6 \pm 1.2$ & $5.2 \pm 1.2$ & 0.009 \\
TAC $(\mathrm{mmol} / \mathrm{L})$ & $23.8 \pm 16.3$ & $30.5 \pm 16.3$ & 0.78 \\
GSH $(\mu \mathrm{mol} / \mathrm{L})$ & $26.3 \pm 15.8$ & $25.7 \pm 15.8$ & 0.98 \\
MDA $(\mu \mathrm{mol} / \mathrm{L})$ & $0.4 \pm 0.2$ & $-0.1 \pm 0.2$ & 0.02 \\
\hline
\end{tabular}

All values are means \pm SEs. Values are adjusted for baseline values, age and BMI at baseline

a Obtained from ANCOVA

DHEAS dehydroepiandrosterone sulfate, $F A l$ free androgen index, GSH total glutathione, $h s$-CRP high-sensitivity C-reactive protein, $m F-G$ modified Ferriman Gallwey, MDA malondialdehyde, NO nitric oxide, SHBG sex hormone-binding globulin, TAC total antioxidant capacity 
synbiotic among adults with nonalcoholic fatty liver disease over 28 weeks inhibited inflammatory markers [36]. Consumption of the synbiotic bread for 2 months in people with T2DM significantly increased plasma levels of $\mathrm{NO}$ and decreased MDA, but unchanged TAC, GSH, catalase concentrations [9]. These findings were similar in pregnant women [37] and patients with rheumatoid arthritis [38]. Furthermore, soy milk containing probiotic for $48 \mathrm{~h}$ increased NO production in human endothelial cells [39]. A significant decline in MDA values was also evidenced after the intake of probiotic in rabbits for 30 days [40]. However, synbiotic supplementation for 6 weeks did not influence CRP values [41]. In addition, NO status did not affect by probiotic in herpes simplex virus type 1 [42]. Supplementation with probiotic supplements for 7 days did not decrease MDA values [43]. Elevated inflammatory markers in subjects with PCOS would result in increased risk of atherosclerosis, diabetes and infertility [44]. In addition, oxidative stress is correlated with obesity and hyperandrogenism [45]. Increased oxidative stress could also induce directly genetic variation by DNA damage, and epigenetic change including elevated DNA methylation levels, which both play important roles in the pathogenesis of cancer [46, 47]. Upregulation of IL-18 by SCFA products [48] and elevated production of methylketones in gut by synbiotic [49] might decrease inflammatory markers. Decreased hydroperoxides by synbiotic intake may elevate NO levels [50, 51]. Moreover, synbiotic intake may reduce MDA because its impact on decreased lipid parameters [52] and inhibiting lipid peroxidation reactions [53, 54].

Limitations of our study include the absent of testing for a dose-response relationship between synbiotic intake and occurred changes in the metabolic profiles. Furthermore, we did not determine the effects of synbiotic on other metabolic parameters. However, duration of the treatment was too short to determine the effects of synbiotic on hormonal parameters and $\mathrm{mFG}$ scores; we believe that future studies with cross-over design and longer duration of the intervention are required to prove our findings. Furthermore, the high standard deviations (SDs) of dependent parameters in some cases might be due to the small number of participants in the study.

\section{Conclusions}

Overall, synbiotic supplementation for 12 weeks in PCOS women had beneficial effects on SHBG, mFG scores, FAI, hs-CRP and NO levels, but did not affect other hormonal status and biomarkers of oxidative stress.

\section{Abbreviations}

CVD: Cardiovascular disease; CVs: Coefficient variances;

DHEAS: Dehydroepiandrosterone sulfate; FAl: Free androgen index:

GDM: Gestational diabetes; GSH: Total glutathione; hs-CRP: High-sensitivity C- reactive protein; MDA: Malondialdehyde; $\mathrm{mF-G}$ : Modified Ferriman Gallwey; NO: Nitric oxide; PCOS: Polycystic ovary syndrome; SCFA: Short chain fatty acid; SHBG: Sex hormone-binding globulin; T2DM: Type 2 diabetes mellitus; TAC: Total antioxidant capacity

\section{Acknowledgements}

The present study was supported by a grant from the Vice-chancellor for Research, AUMS, Arak, and Iran.

\section{Funding}

The research grant provided by Research Deputy of Arak University of Medical Sciences (AUMS).

\section{Availability of data and materials}

The primary data for this study is available from the authors on direct request.

\section{Authors' contributions}

ZA contributed in conception, design, statistical analysis and drafting of the manuscript. KhN, MJ, ER, FB and MT-E contributed in data collection and manuscript drafting. All authors approved the final version for submission. ZA supervised the study.

\section{Ethics approval and consent to participate}

The study was conducted according to the ethical guidelines of the Declaration of Helsinki (the ethical standards of the institutional and national research committee and with the 1964 Helsinki declaration and its later amendments) and was approved by the ethics committee of the Arak University of Medical Sciences (AUMS), Arak, Iran (http://www.irct.ir: IRCT201509115623N53). All participants provided a written informed consent.

\section{Competing interests}

The authors declare that they have no competing interests.

\section{Publisher's Note}

Springer Nature remains neutral with regard to jurisdictional claims in published maps and institutional affiliations.

\section{Author details}

${ }^{1}$ Endocrinology and Metabolism Research Center, Arak University of Medical Sciences, Arak, Iran. ${ }^{2}$ Research Center for Biochemistry and Nutrition in Metabolic Diseases, Kashan University of Medical Sciences, Kashan, IR, Iran. ${ }^{3}$ Faculty member of Science department, Science Faculty, Islamic Azad University, Tehran Central Branch, Tehran, Iran.

Received: 12 January 2018 Accepted: 6 April 2018

Published online: 12 April 2018

\section{References}

1. Clark NM, Podolski AJ, Brooks ED, et al. Prevalence of polycystic ovary syndrome phenotypes using updated criteria for polycystic ovarian morphology: an assessment of over 100 consecutive women self-reporting features of polycystic ovary syndrome. Reprod Sci. 2014;21:1034-43.

2. Duleba AJ, Dokras A. Is PCOS an inflammatory process? Fertil Steril. 2012;97:7-12.

3. Boots $C E$, Jungheim ES. Inflammation and human ovarian follicular dynamics. Semin Reprod Med. 2015;33:270-5.

4. Akram Kooshki A, Tofighiyan T, Rakhshani MH. Effects of Synbiotics on inflammatory markers in patients with type 2 diabetes mellitus. Glob J Health Sci. 2015;7:1-5.

5. Ahmadi S, Jamilian M, Tajabadi-Ebrahimi M, et al. The effects of synbiotic supplementation on markers of insulin metabolism and lipid profiles in gestational diabetes: a randomised, double-blind, placebo-controlled trial. Br J Nutr. 2016;116:1394-401.

6. Saez-Lara MJ, Robles-Sanchez C, Ruiz-Ojeda FJ, et al. Effects of probiotics and Synbiotics on obesity, insulin resistance syndrome, type 2 diabetes and non-alcoholic fatty liver disease: a review of human clinical trials. Int J Mol Sci. 2016;17:928.

7. Tanaka $\mathrm{K}$, Yano M, Motoori M, et al. Impact of perioperative administration of synbiotics in patients with esophageal cancer undergoing 
esophagectomy: a prospective randomized controlled trial. Surgery. 2012; 152:832-42.

8. Cani PD, Delzenne NM. Involvement of the gut microbiota in the development of low grade inflammation associated with obesity: focus on this neglected partner. Acta Gastroenterol Belg. 2010;73:267-9.

9. Bahmani F, Tajadadi-Ebrahimi M, Kolahdooz F, et al. The consumption of synbiotic bread containing lactobacillus sporogenes and inulin affects nitric oxide and malondialdehyde in patients with type 2 diabetes mellitus: randomized, double-blind, placebo-controlled trial. J Am Coll Nutr. 2016;35: 506-13.

10. Ipar N, Aydogdu SD, Yildirim GK, et al. Effects of synbiotic on anthropometry, lipid profile and oxidative stress in obese children. Benef Microbes. 2015;6:775-82.

11. Lamprecht M, Bogner S, Schippinger $G$, et al. Probiotic supplementation affects markers of intestinal barrier, oxidation, and inflammation in trained men; a randomized, double-blinded, placebo-controlled trial. J Int Soc Sports Nutr. 2012;9:45

12. Voltolini C, Battersby S, Etherington SL, et al. A novel antiinflammatory role for the short-chain fatty acids in human labor. Endocrinology. 2012; 153:395-403.

13. Matthews GM, Howarth GS, Butler RN. Short-chain fatty acid modulation of apoptosis in the Kato III human gastric carcinoma cell line. Cancer Biol Ther. 2007;6(7):1051.

14. Rotterdam ESHRE. ASRM-sponsored PCOS consensus workshop group. Revised 2003 consensus on diagnostic criteria and long-term health risks related to polycystic ovary syndrome. Fertil Steril. 2004;81:19-25.

15. Huang A, Brennan K, Azziz R. Prevalence of hyperandrogenemia in the polycystic ovary syndrome diagnosed by the National Institutes of Health 1990 criteria. Fertil Steril. 2010;93:1938-41.

16. Ahmadi S, Jamilian M, Karamali M, et al. Probiotic supplementation and the effects on weight loss, glycaemia and lipid profiles in women with polycystic ovary syndrome: a randomized, double-blind, placebo-controlled trial. Hum Fertil (Camb). 2017;20:254-61.

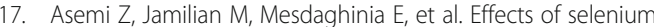
supplementation on glucose homeostasis, inflammation, and oxidative stress in gestational diabetes: randomized, double-blind, placebo-controlled trial. Nutrition. 2015;31:1235-42.

18. Hatch R, Rosenfield RL, Kim MH, et al. Hirsutism: implications, etiology, and management. Am J Obstet Gynecol. 1981;140:815-30.

19. Tatsch E, Bochi GV, Pereira Rda S, et al. A simple and inexpensive automated technique for measurement of serum nitrite/nitrate. Clin Biochem. 2011:44:348-50.

20. Benzie IF, Strain JJ. The ferric reducing ability of plasma (FRAP) as a measure of "antioxidant power": the FRAP assay. Anal Biochem. 1996;239:70-6.

21. Beutler E, Gelbart T. Plasma glutathione in health and in patients with malignant disease. J Lab Clin Med. 1985;105:581-4.

22. Janero DR. Malondialdehyde and thiobarbituric acid-reactivity as diagnostic indices of lipid peroxidation and peroxidative tissue injury. Free Radic Biol Med. 1990;9:515-40.

23. Pisprasert $\mathrm{V}$, Ingram KH, Lopez-Davila MF, et al. Limitations in the use of indices using glucose and insulin levels to predict insulin sensitivity: impact of race and gender and superiority of the indices derived from oral glucose tolerance test in African Americans. Diabetes Care. 2013;36:845-53.

24. Asemi Z, Khorrami-Rad A, Alizadeh SA, et al. Effects of synbiotic food consumption on metabolic status of diabetic patients: a double-blind randomized cross-over controlled clinical trial. Clin Nutr. 2014;33:198-203.

25. Asemi Z, Foroozanfard F, Hashemi T, et al. Calcium plus vitamin D supplementation affects glucose metabolism and lipid concentrations in overweight and obese vitamin D deficient women with polycystic ovary syndrome. Clin Nutr. 2015;34:586-92.

26. Foroozanfard F, Jamilian M, Bahmani F, et al. Calcium plus vitamin D supplementation influences biomarkers of inflammation and oxidative stress in overweight and vitamin D-deficient women with polycystic ovary syndrome: a randomized double-blind placebo-controlled clinical trial. Clin Endocrinol. 2015;83:888-94

27. Shoaei T, Heidari-Beni M, Tehrani HG. Effects of probiotic supplementation on pancreatic $\beta$-cell function and c-reactive protein in women with polycystic ovary syndrome: a randomized double-blind placebo-controlled clinical trial. International journal of preventive medicine. 2015;6:27.

28. Eslamparast T, Zamani F, Hekmatdoost A, et al. Effects of synbiotic supplementation on insulin resistance in subjects with the metabolic syndrome: a randomised, double-blind, placebo-controlled pilot study. $\mathrm{Br}$ J Nutr. 2014;112:438-45.

29. Moroti C, Souza Magri LF, de Rezende Costa M, et al. Effect of the consumption of a new symbiotic shake on glycemia and cholesterol levels in elderly people with type 2 diabetes mellitus. Lipids Health Dis. 2012;11:29.

30. De Leo V, Musacchio MC, Cappelli V, et al. Genetic, hormonal and metabolic aspects of PCOS: an update. Reprod Biol Endocrinol. 2016;14:38.

31. Walters KA, Allan CM, Handelsman DJ. Androgen actions and the ovary. Biol Reprod. 2008;78:380-9.

32. Azzolin GC, Saiduddin S. Effect of androgens on the ovarian morphology of the hypophysectomized rat. Proc Soc Exp Biol Med. 1983;172:70-3.

33. Gonzalez F, Sia CL, Bearson DM, et al. Hyperandrogenism induces a proinflammatory TNFalpha response to glucose ingestion in a receptordependent fashion. J Clin Endocrinol Metab. 2014;99:E848-54.

34. Compare D, Coccoli P, Rocco A, et al. Gut-liver axis: the impact of gut microbiota on non alcoholic fatty liver disease. Nutr Metab Cardiovasc Dis. 2012;22(6):471.

35. Li Z, Yang S, Lin H, et al. Probiotics and antibodies to TNF inhibit inflammatory activity and improve nonalcoholic fatty liver disease. Hepatology. 2003;37:343-50

36. Eslamparast T, Poustchi H, Zamani F, et al. Synbiotic supplementation in nonalcoholic fatty liver disease: a randomized, double-blind, placebocontrolled pilot study. Am J Clin Nutr. 2014;99:535-42.

37. Asemi Z, Jazayeri S, Najafi M, et al. Effect of daily consumption of probiotic yogurt on oxidative stress in pregnant women: a randomized controlled clinical trial. Ann Nutr Metab. 2012;60:62-8.

38. Zamani B, Golkar HR, Farshbaf S, et al. Clinical and metabolic response to probiotic supplementation in patients with rheumatoid arthritis: a randomized, double-blind, placebo-controlled trial. Int J Rheum Dis. 2016;19:869-79

39. Cheng CP, Tsai SW, Chiu CP, et al. The effect of probiotic-fermented soy milk on enhancing the NO-mediated vascular relaxation factors. J Sci Food Agric. 2013;93:1219-25.

40. Ghoneim MA, Moselhy SS. Antioxidant status and hormonal profile reflected by experimental feeding of probiotics. Toxicol Ind Health. 2016:32:741-50.

41. Holma R, Kekkonen RA, Hatakka K, et al. Low serum enterolactone concentration is associated with low colonic lactobacillus-enterococcus counts in men but is not affected by a synbiotic mixture in a randomised, placebo-controlled, double-blind, cross-over intervention study. Br J Nutr. 2014;111:301-9.

42. Khani S, Motamedifar M, Golmoghaddam H, et al. In vitro study of the effect of a probiotic bacterium lactobacillus rhamnosus against herpes simplex virus type 1. Braz J Infect Dis. 2012;16:129-35.

43. Ebrahimi-Mameghani M, Sanaie S, Mahmoodpoor A, et al. Effect of a probiotic preparation (VSL\#3) in critically ill patients: a randomized, doubleblind, placebo-controlled trial (pilot study). Pak J Med Sci. 2013;29:490-4.

44. Pawelczak M, Rosenthal J, Milla S, et al. Evaluation of the pro-inflammatory cytokine tumor necrosis factor-alpha in adolescents with polycystic ovary syndrome. J Pediatr Adolesc Gynecol. 2014;27:356-9.

45. Valmadrid CT, Klein R, Moss SE, et al. The risk of cardiovascular disease mortality associated with microalbuminuria and gross proteinuria in persons with older-onset diabetes mellitus. Arch Intern Med. 2000;160:1093-100.

46. Filippone EJ, Gupta A, Farber JL. Normoglycemic diabetic nephropathy: the role of insulin resistance. Case Rep Nephrol Urol. 2014;4:137-43.

47. Lu HJ, Tzeng TF, Liou SS, et al. Polysaccharides from Liriopes Radix ameliorate streptozotocin-induced type I diabetic nephropathy via regulating NF-kappaB and p38 MAPK signaling pathways. BMC Complement Altern Med. 2014;14:156.

48. Kalina U, Koyama N, Hosoda T, et al. Enhanced production of IL-18 in butyrate-treated intestinal epithelium by stimulation of the proximal promoter region. Eur J Immunol. 2002;32:2635-43.

49. Vitali B, Ndagijimana M, Cruciani F, et al. Impact of a synbiotic food on the gut microbial ecology and metabolic profiles. BMC Microbiol. 2010;10:4

50. Komers R, Anderson S. Paradoxes of nitric oxide in the diabetic kidney. Am J Physiol Renal Physiol. 2003;284:F1121-37.

51. Szkudelski T. The mechanism of alloxan and streptozotocin action in B cells of the rat pancreas. Physiol Res. 2001;50:537-46.

52. Shakeri $\mathrm{H}$, Hadaegh $\mathrm{H}$, Abedi $\mathrm{F}$, et al. Consumption of synbiotic bread decreases triacylglycerol and VLDL levels while increasing $\mathrm{HDL}$ levels in serum from patients with type-2 diabetes. Lipids. 2014;49:695-701. 
53. Wang Y, Li Y, Xie J, et al. Protective effects of probiotic lactobacillus casei Zhang against endotoxin- and d-galactosamine-induced liver injury in rats via anti-oxidative and anti-inflammatory capacities. Int Immunopharmacol. 2013;15:30-7.

54. Zhai $\mathrm{Q}$, Wang $\mathrm{G}$, Zhao J, et al. Protective effects of lactobacillus plantarum CCFM8610 against acute cadmium toxicity in mice. Appl Environ Microbiol. 2013;79:1508-15.

Ready to submit your research? Choose BMC and benefit from:

- fast, convenient online submission

- thorough peer review by experienced researchers in your field

- rapid publication on acceptance

- support for research data, including large and complex data types

- gold Open Access which fosters wider collaboration and increased citations

- maximum visibility for your research: over $100 \mathrm{M}$ website views per year 